\title{
Alelopatia de Leucena sobre soja e plantas invasoras
}

\section{Leucaena allelopathy on weeds and soybean seed germination}

\author{
Márcia Maria Mauli ${ }^{1}$; Andréa Maria Teixeira Fortes ${ }^{2 *}$; \\ Danielle Medina Rosa ${ }^{3}$; Gislaine Piccolo 3 ; Denise Sommer Marques ${ }^{4}$; \\ Jaqueline Malagutti Corsato ${ }^{4}$; Raquel Leszczynski ${ }^{5}$
}

\section{Resumo}

Com o desenvolvimento da agricultura surgiram os conseqüentes aumentos na degradação ambiental. Assim, estuda-se a utilização de plantas que possuam em sua composição química substâncias capazes de auxiliar no controle de plantas invasoras, amenizando o uso de agrotóxicos. Desta forma, o objetivo do trabalho foi avaliar soluções de extratos de leucena sobre plantas invasoras que freqüentemente ocorrem na cultura da soja. Foram utilizados como tratamentos os seguintes extratos de leucena nas proporções de: $0,20,40,60,80$ e 100\% com água à temperatura ambiente e com água aquecida à $80^{\circ} \mathrm{C}$. Os extratos foram obtidos triturando-se $200 \mathrm{~g}$ de folhas de leucena em um litro de água destilada, com auxílio de um liquidificador. As sementes foram mantidas em B.O.D. à temperatura de $25^{\circ} \mathrm{C}$, com fotoperíodo de 12 horas de luz. As avaliações foram diárias, do primeiro ao último dia de experimento, este variando conforme a espécie. Os resultados demonstraram interferência negativa dos extratos, tanto quente quanto frio, no comprimento de raiz de corda de viola, na porcentagem de germinação e no comprimento de raiz de guanxuma e picão-preto. Não foram constatadas interferências negativas nos parâmetros analisados para as sementes de soja. Sendo assim, os resultados obtidos indicam potencial alelopático da espécie Leucaena leuucocephala como alternativa de manejo de plantas invasoras sem interferir no desenvolvimento da cultura da soja.

Palavras-chave: Alelopatia, Leucaena leucocephala, Glycine max

\begin{abstract}
With the advance of agriculture, there was consequent rising in environment degradation. Therefore, It is interesting the use of plants which have in their chemical composition substances capable of helping in the control of weeds to minimize the use of pesticides. Hence, the objective of this paper was to evaluate solutions of leucena extract on weeds that are frequent on soybean crop. The treatments were leucena extracts at $0,20,40,60,80$ and $100 \%$ at room temperature water and water heated to $80^{\circ} \mathrm{C}$. The extracts were obtained by crushing $200 \mathrm{~g}$ of leucena leaves and mixing them with one liter of distilled water with the help of a blender. Seeds were kept in B.O.D. at a temperature of $25^{\circ} \mathrm{C}$, with a photoperiod of 12 hours of light. Evaluations were done on a daily basis, from the first to the last day of the experiment, varying according to the species. Results show a negative interference of the extracts, both hot and cold, in the root length of Ipomoea grandifolia, in the percentage of germination and in the root length of Arrowleaf sida and Hair beggarticks. There was no negative interference in the analyzed
\end{abstract}

\footnotetext{
1 Bióloga, estudante de pós-graduação da Unioeste-Cascavel/PR. E-mail: marcia.m.mauli@gmail.com

2 Bióloga, Doutora, Professor adjunto - Unioeste - Cascavel/PR. E-mail: amtfortes@unioeste.br. Rua Universitária, 2069. CEP: 85819-110 - Cascavel - PR

3 Bióloga, estudante de pós-graduação da Unioeste - Cascavel/PR.

4 Bióloga, estudante de pós-graduação da Unesp -Botucatu/SP.

5 Bióloga, estudante de pós-graduação UEM - Maringá/PR.

* Autor para correspondência
} 
parameters for soybean seeds. Thus, the results indicate allelopatic potential of Leucaena leuисосерhala as an alternative for the management of weeds without interfering on the development of the soybean crop.

Key words: Allelopathy, Leucaena leucocephala, Glycine max

\section{Introdução}

O controle de plantas invasoras é uma prática de grande importância para a obtenção de altos rendimentos em qualquer exploração agrícola e tão antiga quanto a própria agricultura. São definidas como espécies que crescem onde não são desejadas, ou seja, grupo de plantas que crescem espontaneamente em solos agrícolas e em outras áreas de interesse do homem (LORENZI, 2000).

A soja (Glycine max L. MERRIL) e as plantas invasoras, entre elas a guanxuma (Sida rhombifolia L.), a corda de viola [Ipomoea grandifolia (Dammer) O’ Donell] e o picão-preto (Bidens pilosa L.), constituem comunidades dinâmicas que são definidas por fatores como temperatura, luz, oxigênio e água; e por interações que se estabelecem entre eles, denominadas de interferências, dentre elas destaca-se a alelopatia (MULLER, 1996 citado por ALMEIDA, 1988). Alelopatia é a capacidade das plantas produzirem substâncias químicas que podem influenciar outras, favorável ou desfavoravelmente, quando liberadas no ambiente (MONTEIRO; VIEIRA, 2002).

Os compostos alelopáticos afetam mais de uma função no organismo atingido, dentre eles podese mencionar redução na absorção de nutrientes, alteração nos hormônios de crescimento, inibição da fotossíntese, alterações no processo respiratório acelerando ou diminuindo a respiração, efeitos na síntese de proteínas, alterações na permeabilidade da membrana e inibição da atividade enzimática (MONTEIRO; VIEIRA, 2002). O estudo de compostos alelopáticos vem progredindo nos últimos anos na perspectiva da sua manipulação para aplicações práticas na agricultura, como por exemplo, para controlar pragas e plantas invasoras (MALLIK; OLOFSDOTTER, 2001).
O efeito alelopático de leucena inibindo a germinação e/ou crescimento de plantas invasoras sugere sua utilização como alternativa de controle, não só pelo uso de um agente químico natural, mas também pela presença de novos grupamentos químicos nas substâncias isoladas, as quais podem ser manipuladas pela indústria, de maneira a descobrir novas moléculas com efeito herbicida (PIRES et al., 2001). Conforme comprovado por Chou e Kuo (1986), a leucena apresenta notória atividade alelopática, atribuída ao aleloquímico mimosina.

A leucena apresenta várias utilizações como no reflorestamento de áreas degradadas, melhorando as qualidades físico-químicas e biológicas do solo, assim como na alimentação de caprinos, adubação verde, etc (PRATES et al., 2000). É uma espécie exótica, largamente encontrada ao longo de rodovias, em áreas degradadas, em áreas agrícolas, em pastagens e em afloramentos rochosos (INSTITUTO HORUS DE DESENVOLVIMENTO E CONSERVAÇÃO, 2003).

Muitos são os danos causados pelas espécies exóticas, dentre eles podemos citar exaustão dos recursos hídricos, dizimação de plantações, destruição de florestas, extinção de espécies, poluição, destruição de pastagens, entre muitos outros. Os prejuízos normalmente são superiores aos ganhos obtidos com a introdução e uso destas espécies (INSTITUTO HORUS DE DESENVOLVIMENTO E CONSERVAÇÃO, 2003). E esses efeitos "ecologicamente danosos e economicamente custosos" só aparecem a médio e longo prazo segundo Siqueira (2006), levando a um problema ambiental cada vez mais complexo e difícil de ser corrigido. 
Nesse sentido, buscam-se soluções que possam diminuir o uso excessivo de produtos químicos prejudiciais ao meio ambiente, agricultor e consumidor, através de produtos naturais para combater as plantas invasoras na cultura da soja. O objetivo do presente trabalho foi avaliar o potencial alelopático da espécie leucena [Leucaena leucocephala (Lam.) R. de Wit.] sobre a espécie bioindicadora alface (Lactuca sativa L.), as plantas invasoras corda de viola (Ipomoea grandifolia), guanxuma (Sida rhombifolia L.) e picão-preto (Bidens pilosa L.) e a cultura da soja.

\section{Materiais e Métodos}

O experimento foi realizado no laboratório de Fisiologia Vegetal da UNIOESTE, localizado no Campus de Cascavel/PR, no período de novembro de 2005 à agosto de 2006.

As plantas invasoras utilizadas para o experimento foram a corda de viola, a guanxuma, e o picão-preto, que são invasoras da cultura de soja, também utilizada neste experimento.

Para a produção dos extratos aquosos quente e frio, foram trituradas folhas de leucena com o auxílio de um liquidificador, na proporção de 200 gramas de folhas para 1L de água destilada. Para o experimento caracterizado como extrato frio, foi utilizada água em temperatura ambiente; e, para o extrato quente, água em temperatura de $80^{\circ} \mathrm{C}$ para preparo do extrato, entretanto, só depois de atingir temperatura ambiente é que foi aplicado nas sementes.

A câmara de germinação foi mantida a $25^{\circ} \mathrm{C}$ com variaçao de $2^{\circ} \mathrm{C}$ e com fotoperíodo de 12 horas de luz. Os meios de germinação (papel germiteste, placa de petri com papel filtro) foram autoclavados à $121^{\circ} \mathrm{C}$ por 20 minutos. As avaliações foram feitas em intervalos de 24 horas, considerando-se como semente germinada aquela que apresentar radícula com aproximadamente dois milímetros de comprimento (HADAS, 1976), do primeiro ao último dia de experimento, este variando conforme a espécie. Nas placas de petri foram adicionados 10 $\mathrm{ml}$ do extrato e nos rolos de germiteste 2,5 vezes o peso do papel. Do total de sementes, apenas $5 \mathrm{de}$ cada repetição foram avaliadas para obtenção das médias referentes ao comprimento da raiz primária. Onze tratamentos foram realizados para cada espécie em estudo sendo: 0; 20, 40, 60, 80 e 100\% com água à temperatura ambiente; e 20,40,60, 80 e $100 \%$ com água aquecida à $80^{\circ} \mathrm{C}$. O trabalho foi dividido em três experimentos.

No primeiro experimento, avaliaram-se os efeitos de dos extratos de leucena sobre alface, em que foram verificadas a presença de aleloquímicos na leucena e a diferença na utilização de água quente ou fria para preparo dos extratos, utilizando extratos aquosos de leucena sobre as sementes de alface, espécie esta indicadora da presença de aleloquímicos.

Vinte e cinco sementes de alface foram utilizadas em placas de petri com três folhas de papel filtro como meio de germinação, sendo as mesmas analisadas do $1^{\circ}$ ao $4^{\circ}$ dia de experimento.

No segundo experimento utilizando extrato de leucena, para quebra de dormência das sementes de corda de viola e guanxuma foi utilizado ácido sulfúrico por 10 e 5 minutos, respectivamente, baseando-se em estudos realizados por Azania et al. (2003) e Souza Filho, Rodrigues e Rodrigues (1997). Para as sementes de picão-preto não foi utilizada quebra de dormência.

As avaliações foram realizadas do primeiro ao último dia de experimento, considerando-se na totalidade de 7, 9 e 10 dias respectivamente, para as espécies corda de viola, guanxuma e picão-preto.

No terceiro experimento, leucena sobre soja, foram feitos experimentos utilizando extratos aquosos sobre as sementes desta espécie, para avaliar se há interferência de leucena sobre a planta cultivada. Foram utilizados rolos de papel germiteste, com 50 sementes em cada repetição. 
Os extratos aquosos foram obtidos da mesma forma descrita anteriormente. As avaliações foram feitas 24 horas após a colocação dos rolos de papel germiteste na B.O.D. até o $7^{\circ}$ dia de experimento.

Para todos os três experimentos, o delineamento experimental foi inteiramente casualizado, com quatro repetições cada.

Os dados obtidos para porcentagem de germinação foram submetidos à análise de variância (teste $\mathrm{F}$ ), utilizando-se a transformação arco seno da raiz quadrada de $\mathrm{x} / 100$, sendo as médias comparadas com o teste Tukey a $5 \%$ de probabilidade (PIMENTEL-GOMES, 1990). Além disso, foram feitas observações quanto ao tempo médio de germinação calculados segundo Edmond e Drapalla (1958) e a velocidade média de germinação, de acordo com Labouriau (1983).

\section{Resultados e Discussão}

Para os extratos de leucena sobre alface (Tabela 1) observou-se que, as soluções aquosas quente e fria de folhas interferiram significativamente na porcentagem de germinação e comprimento de raiz de sementes de alface quando comparados com o controle, havendo redução de ambas características com o aumento da concentração dos extratos. Apenas o comprimento de raiz exposto ao extrato quente $20 \%$ não diferiu do controle. Constatouse também inibição total de todos os parâmetros analisados do extrato frio nas concentrações $60 \%$, $80 \%$ e $100 \%$. Entretanto, o extrato quente não teve diferenças significativas no tempo médio e na velocidade média de germinação das sementes de alface, e o extrato frio interferiu negativamente a partir da concentração $60 \%$ na velocidade média de germinação. Esses dados corroboram com Chou e Kuo (1986), que comprovaram que as folhas de leucena apresentam fitotoxidade sobre o alface. Estes resultados comprovam também os obtidos por Scherer et al. (2005) que já haviam constatado anteriormente a atividade alelopática de leucena sobre espécies arbóreas como a canafístula (Peltophorum dubium Spreng), mostrando que a leucena pode interferir em algumas espécies influenciando sua germinação ou desenvolvimento.

Tabela 1. Porcentagem, tempo médio, velocidade média de germinação submetidas aos extratos aquosos frio e quente de leucena (Leucaena leucocephala) sobre alface (Lactuca sativa L.).

\begin{tabular}{ccccc}
\hline Tratamentos & $\begin{array}{c}\text { Porcentagem de } \\
\text { germinação (\%) }\end{array}$ & $\begin{array}{c}\text { Tempo Médio } \\
\text { (Dias) }\end{array}$ & $\begin{array}{c}\text { Velocidade Média } \\
\text { (Sementes/dia) }\end{array}$ & $\begin{array}{c}\text { Comprimento de } \\
\text { Raiz (cm) }\end{array}$ \\
\hline Testemunha & $74 \mathrm{a}$ & $2,35 \mathrm{ab}$ & $0,44 \mathrm{a}$ & $1,50 \mathrm{a}$ \\
Ext. frio $-20 \%$ & $25 \mathrm{c}$ & $2,96 \mathrm{a}$ & $0,35 \mathrm{ab}$ & $0,27 \mathrm{~b}$ \\
Ext. frio $-40 \%$ & $6 \mathrm{~d}$ & $2,21 \mathrm{ab}$ & $0,30 \mathrm{ab}$ & $0,15 \mathrm{~b}$ \\
Ext. frio $-60 \%$ & $0 \mathrm{~d}$ & $0 \mathrm{~b}$ & $0 \mathrm{~b}$ & $0 \mathrm{~b}$ \\
Ext. frio $-80 \%$ & $0 \mathrm{~d}$ & $0 \mathrm{~b}$ & $0 \mathrm{~b}$ & $0 \mathrm{~b}$ \\
Ext. frio $-100 \%$ & $0 \mathrm{~d}$ & $0 \mathrm{~b}$ & $0 \mathrm{~b}$ & $0 \mathrm{~b}$ \\
Ext. quente- $-20 \%$ & $51 \mathrm{~b}$ & $2,65 \mathrm{a}$ & $0,38 \mathrm{a}$ & $1,09 \mathrm{a}$ \\
Ext. quente- $-40 \%$ & $16 \mathrm{~cd}$ & $2,98 \mathrm{a}$ & $0,38 \mathrm{a}$ & $0,26 \mathrm{~b}$ \\
Ext. quente- $-60 \%$ & $10 \mathrm{~cd}$ & $3 \mathrm{a}$ & $0,46 \mathrm{a}$ & $0,28 \mathrm{~b}$ \\
Ext. quente- $-80 \%$ & $1 \mathrm{~d}$ & $1 \mathrm{ab}$ & $0,06 \mathrm{ab}$ & $0,05 \mathrm{~b}$ \\
Ext. quente- $-100 \%$ & $4 \mathrm{~d}$ & $2,5 \mathrm{ab}$ & $0,29 \mathrm{ab}$ & $0,15 \mathrm{~b}$ \\
\hline
\end{tabular}

Médias seguidas da mesma letra não diferem significativamente entre si pelo teste de Tukey, a $5 \%$ de probabilidade 
Sendo assim, pode-se sugerir a existência do potencial alelopático de folhas de leucena, pela sensibilidade observada nas sementes de alface, espécie esta usada por ser indicadora da presença de aleloquímicos, aos extratos tanto quente quanto frio.

Para os extratos de leucena sobre plantas invasoras, o comprimento de raiz da espécie corda de viola (Tabela 2) apresentou maior interferência dos extratos de leucena, podendo-se observar menor comprimento de raiz principalmente quando submetido ao extrato quente comparando com o controle, apesar dos tratamentos não terem diferido entre si. Os extratos frio a $100 \%$ e quente a $80 \%$ e $100 \%$ aumentaram o tempo médio de germinação da espécie, enquanto para a velocidade média, a partir de $60 \%$ dos extratos, ocorreu redução, apesar da porcentagem de germinação não ter sido influenciada pelos extratos. Verifica-se que a utilização de leucena no controle da corda de viola interferiria provavelmente no seu desenvolvimento e não na sua germinação, isso porque o principal parâmetro afetado foi o comprimento de raiz.

Tabela 2. Porcentagem, tempo médio, velocidade média de germinação submetidas aos extratos aquosos frio e quente de leucena (Leucaena leucocephala) sobre corda de viola [Ipomoea grandifolia (Dammer) O’ Donell].

\begin{tabular}{ccccc}
\hline Tratamentos & $\begin{array}{c}\text { Porcentagem de } \\
\text { germinação (\%) }\end{array}$ & $\begin{array}{c}\text { Tempo Médio } \\
\text { (Dias) }\end{array}$ & $\begin{array}{c}\text { Velocidade Média } \\
\text { (Semente/dia) }\end{array}$ & $\begin{array}{c}\text { Comprimento de } \\
\text { Raiz (cm) }\end{array}$ \\
\hline Testemunha & $96 \mathrm{a}$ & $1,02 \mathrm{c}$ & $0,98 \mathrm{a}$ & $6,85 \mathrm{a}$ \\
Ext. frio $-20 \%$ & $92 \mathrm{a}$ & $1,22 \mathrm{bc}$ & $0,92 \mathrm{abcd}$ & $4,87 \mathrm{a}$ \\
Ext. frio $-40 \%$ & $94 \mathrm{a}$ & $1,27 \mathrm{bc}$ & $0,79 \mathrm{abcd}$ & $2,99 \mathrm{~b}$ \\
Ext. frio- $-60 \%$ & $95 \mathrm{a}$ & $1,56 \mathrm{abc}$ & $0,65 \mathrm{bcde}$ & $1,72 \mathrm{~b}$ \\
Ext. frio- $-80 \%$ & $95 \mathrm{a}$ & $1,51 \mathrm{abc}$ & $0,68 \mathrm{bcde}$ & $1,79 \mathrm{bc}$ \\
Ext. frio- $-100 \%$ & $95 \mathrm{a}$ & $1,67 \mathrm{ab}$ & $0,61 \mathrm{cde}$ & $1,02 \mathrm{~cd}$ \\
Ext. quente- $-20 \%$ & $95 \mathrm{a}$ & $1,18 \mathrm{c}$ & $0,86 \mathrm{abc}$ & $0,80 \mathrm{~cd}$ \\
Ext. quente- $-40 \%$ & $91 \mathrm{a}$ & $1,15 \mathrm{c}$ & $0,87 \mathrm{ab}$ & $0,52 \mathrm{~d}$ \\
Ext. quente- $-60 \%$ & $96 \mathrm{a}$ & $1,53 \mathrm{abc}$ & $0,67 \mathrm{bcde}$ & $0,50 \mathrm{~d}$ \\
Ext. quente- $-80 \%$ & $90 \mathrm{a}$ & $1,73 \mathrm{ab}$ & $0,60 \mathrm{de}$ & $0,61 \mathrm{~d}$ \\
Ext. quente- $-100 \%$ & $84 \mathrm{a}$ & $1,97 \mathrm{a}$ & $0,54 \mathrm{e}$ & $0,38 \mathrm{~d}$ \\
\hline
\end{tabular}

Médias seguidas da mesma letra não diferem significativamente entre si pelo teste de Tukey, a 5\% de probabilidade

Almeida (1988) constatou que a espécie corda de viola submetida aos extratos de losna-brava, apresentou diminuição significativa na porcentagem de germinação, indicando que várias são as fases de desenvolvimento que podem sofrer interferência alelopática, assim como outras espécies podem interferir no desenvolvimento e germinação de corda de viola.

O extrato frio de leucena inibiu a porcentagem de germinação de guanxuma a partir da concentração $60 \%$, e o extrato quente a partir de $80 \%$. Entretanto, nenhum dos extratos interferiu significativamente no tempo e velocidade média de germinação.
O comprimento médio da raiz foi influenciado negativamente a partir da concentração 40 e $60 \%$, respectivamente dos extratos frio e quente, sendo que, o extrato frio se mostrou mais eficiente. Os resultados são compatíveis com os descritos por Souza Filho, Rodrigues e Rodrigues (1997), onde o extrato aquoso de sementes e folhas de leucena inibiu a germinação e o alongamento de raiz de guanxuma. Também Borges, Bonaldo e Cruz (1999), verificaram que os extratos aquosos na concentração de $30 \%$ de Eucalyptus citriodora e Cymbopogon citratus, inibiram $60 \%$ da germinação desta espécie. 
Tabela 3. Porcentagem, tempo médio, velocidade média de germinação submetidas aos extratos aquosos frio e quente de leucena (Leucaena leucocephala) sobre guanxuma (Sida rhombifolia L.).

\begin{tabular}{ccccc}
\hline Tratamentos & $\begin{array}{c}\text { Porcentagem de } \\
\text { germinação (\%) }\end{array}$ & $\begin{array}{c}\text { Tempo Médio } \\
\text { (Dias) }\end{array}$ & $\begin{array}{c}\text { Velocidade Média } \\
\text { (Semente/dia) }\end{array}$ & $\begin{array}{c}\text { Comprimento de } \\
\text { Raiz (cm) }\end{array}$ \\
\hline Testemunha & $79 \mathrm{a}$ & $4,06 \mathrm{a}$ & $0,25 \mathrm{a}$ & $3,56 \mathrm{a}$ \\
Ext. frio $-20 \%$ & $81 \mathrm{a}$ & $4,39 \mathrm{a}$ & $0,23 \mathrm{a}$ & $2,77 \mathrm{ab}$ \\
Ext. frio $-40 \%$ & $50 \mathrm{abc}$ & $5,47 \mathrm{a}$ & $0,19 \mathrm{a}$ & $1,80 \mathrm{bcd}$ \\
Ext. frio $-60 \%$ & $27 \mathrm{bcd}$ & $2,10 \mathrm{a}$ & $0,12 \mathrm{a}$ & $0,57 \mathrm{e}$ \\
Ext. frio $-80 \%$ & $7 \mathrm{~d}$ & $5,58 \mathrm{a}$ & $0,20 \mathrm{a}$ & $0,79 \mathrm{de}$ \\
Ext. frio $-100 \%$ & $2 \mathrm{~d}$ & $3,25 \mathrm{a}$ & $0,09 \mathrm{a}$ & $0,22 \mathrm{e}$ \\
Ext. quente $-20 \%$ & $72 \mathrm{a}$ & $3,96 \mathrm{a}$ & $0,25 \mathrm{a}$ & $2,99 \mathrm{ab}$ \\
Ext. quente $-40 \%$ & $62 \mathrm{ab}$ & $5,37 \mathrm{a}$ & $0,19 \mathrm{a}$ & $2,03 \mathrm{abc}$ \\
Ext. quente $-60 \%$ & $63 \mathrm{ab}$ & $6,11 \mathrm{a}$ & $0,16 \mathrm{a}$ & $1,70 \mathrm{bcd}$ \\
Ext. quente $-80 \%$ & $19 \mathrm{~cd}$ & $6,28 \mathrm{a}$ & $0,16 \mathrm{a}$ & $1,05 \mathrm{cde}$ \\
Ext. quente $-100 \%$ & $50 \mathrm{abc}$ & $6,00 \mathrm{a}$ & $0,17 \mathrm{a}$ & $1,71 \mathrm{bcd}$ \\
\hline
\end{tabular}

Médias seguidas da mesma letra não diferem significativamente entre si pelo teste de Tukey, a $5 \%$ de probabilidade

O picão-preto teve sua porcentagem de raiz, a partir de 20 e $40 \%$ com os extratos frio e germinação significativamente reduzida pelos extratos quente e frio de leucena a partir de $40 \%$ de concentração, assim como o comprimento de quente (Tabela 4). A velocidade média foi afetada negativamente apenas a partir de $60 \%$ do extrato quente.

Tabela 4. Porcentagem, tempo médio, velocidade média de germinação submetidas aos extratos aquosos frio e quente de leucena (Leucaena leucocephala.) sobre picão-preto (Bidens pilosa L.).

\begin{tabular}{ccccc}
\hline Tratamentos & $\begin{array}{c}\text { Porcentagem de } \\
\text { germinação (\%) }\end{array}$ & $\begin{array}{c}\text { Tempo Médio } \\
\text { (Dias) }\end{array}$ & $\begin{array}{c}\text { Velocidade Média } \\
\text { (Sementes/dia) }\end{array}$ & $\begin{array}{c}\text { Comprimento de } \\
\text { Raiz (cm) }\end{array}$ \\
\hline Controle & $78 \mathrm{a}$ & $5,06 \mathrm{a}$ & $0,20 \mathrm{ab}$ & $2,80 \mathrm{a}$ \\
Ext. frio $-20 \%$ & $50 \mathrm{ab}$ & $7,57 \mathrm{a}$ & $0,14 \mathrm{ab}$ & $1,44 \mathrm{~b}$ \\
Ext. frio $-40 \%$ & $28 \mathrm{bc}$ & $9,37 \mathrm{a}$ & $0,11 \mathrm{abc}$ & $0,82 \mathrm{bc}$ \\
Ext. frio $-60 \%$ & $26 \mathrm{bc}$ & $9,09 \mathrm{a}$ & $0,11 \mathrm{abc}$ & $1,06 \mathrm{bc}$ \\
Ext. frio $-80 \%$ & $7 \mathrm{c}$ & $4,90 \mathrm{a}$ & $0,05 \mathrm{bc}$ & $0,23 \mathrm{bc}$ \\
Ext. frio $-100 \%$ & $4 \mathrm{c}$ & $7,50 \mathrm{a}$ & $0,07 \mathrm{bc}$ & $0,24 \mathrm{bc}$ \\
Ext. quente $-20 \%$ & $53 \mathrm{ab}$ & $8,55 \mathrm{a}$ & $0,12 \mathrm{abc}$ & $1,48 \mathrm{ab}$ \\
Ext. quente- $-40 \%$ & $29 \mathrm{bc}$ & $9,37 \mathrm{a}$ & $0,11 \mathrm{abc}$ & $1,13 \mathrm{bc}$ \\
Ext. quente- $-60 \%$ & $1 \mathrm{c}$ & $2,25 \mathrm{a}$ & $0,03 \mathrm{c}$ & $0,30 \mathrm{bc}$ \\
Ext. quente- $-80 \%$ & $10 \mathrm{c}$ & $2,40 \mathrm{a}$ & $0,03 \mathrm{c}$ & $0,20 \mathrm{bc}$ \\
Ext. quente $-100 \%$ & $2 \mathrm{c}$ & $2,37 \mathrm{a}$ & $0,03 \mathrm{c}$ & $0,07 \mathrm{c}$ \\
\hline
\end{tabular}

Médias seguidas da mesma letra não diferem significativamente entre si pelo teste de Tukey, a $5 \%$ de probabilidade

Em casa de vegetação, Pires et al. (2001) observaram que, as concentrações 50 e $100 \%$ do extrato de leucena induziram a redução no crescimento da planta de picão-preto e a deformação no seu limbo foliar. Entretanto, constataram que, o extrato aplicado no solo apresentou menor efeito fitotóxico em relação ao aplicado diretamente nas sementes em papel filtro. Segundo Almeida (1988), essa divergência nos resultados ocorre pela presença de microrganismos que degradam as substâncias presentes nos extratos. Assim, verifica-se que em laboratório o resultado pode ser divergente dos obtidos a campo. 
A inibição, por efeito alelopático da cobertura do solocom leucena, da germinação ou desenvolvimento de espécies de plantas invasoras sugere o seu uso como controle alternativo, não só pelo uso do extrato como um agente químico natural, mas também pela possibilidade de isolar grupamentos químicos, os quais podem ser manipulados pelas indústrias de modo a descobrir novas moléculas com efeito herbicida (PIRES et al., 2001).
Para os extratos de leucena sobre soja, constatouse na não ter ocorrido diferenças significativas sobre a soja nos parâmetros porcentagem de germinação e tempo médio. $\mathrm{Na}$ velocidade média, apenas na concentração $60 \%$ do extrato frio, houve um pequeno efeito negativo. No comprimento de raiz o extrato frio não interferiu significativamente.

Tabela 5. Porcentagem, tempo médio, velocidade média de germinação submetidas aos extratos aquosos frio e quente de leucena (Leucaena leucocephala) sobre soja (Glycine max L. MERRIL).

\begin{tabular}{ccccc}
\hline Tratamentos & $\begin{array}{c}\text { Porcentagem de } \\
\text { germinação (\%) }\end{array}$ & $\begin{array}{c}\text { Tempo Médio } \\
\text { (Dias) }\end{array}$ & $\begin{array}{c}\text { Velocidade Média } \\
\text { (Sementes/dia) }\end{array}$ & $\begin{array}{c}\text { Comprimento de } \\
\text { Raiz (cm) }\end{array}$ \\
\hline Testemunha & $88 \mathrm{a}$ & $1,79 \mathrm{ab}$ & $0,56 \mathrm{ab}$ & $9,33 \mathrm{de}$ \\
Ext. frio $-20 \%$ & $88 \mathrm{a}$ & $1,74 \mathrm{~b}$ & $0,57 \mathrm{a}$ & $9,09 \mathrm{de}$ \\
Ext. frio $-40 \%$ & $92 \mathrm{a}$ & $2,05 \mathrm{ab}$ & $0,48 \mathrm{bc}$ & $10,66 \mathrm{~cd}$ \\
Ext. frio $-60 \%$ & $92 \mathrm{a}$ & $2,12 \mathrm{a}$ & $0,47 \mathrm{c}$ & $8,43 \mathrm{de}$ \\
Ext. frio $-80 \%$ & $95 \mathrm{a}$ & $1,90 \mathrm{ab}$ & $0,52 \mathrm{abc}$ & $9,38 \mathrm{de}$ \\
Ext. frio $-100 \%$ & $88 \mathrm{a}$ & $2,06 \mathrm{ab}$ & $0,48 \mathrm{bc}$ & $7,62 \mathrm{e}$ \\
Ext. Quente $-20 \%$ & $89 \mathrm{a}$ & $1,99 \mathrm{ab}$ & $0,51 \mathrm{abc}$ & $15,48 \mathrm{a}$ \\
Ext. Quente- $-40 \%$ & $93 \mathrm{a}$ & $1,99 \mathrm{ab}$ & $0,50 \mathrm{abc}$ & $13,17 \mathrm{abc}$ \\
Ext. Quente- $-60 \%$ & $95 \mathrm{a}$ & $1,86 \mathrm{ab}$ & $0,54 \mathrm{abc}$ & $13,55 \mathrm{ab}$ \\
Ext. Quente $-80 \%$ & $99 \mathrm{a}$ & $2,09 \mathrm{ab}$ & $0,48 \mathrm{bc}$ & $12,60 \mathrm{bc}$ \\
Ext. quente- $-100 \%$ & $98 \mathrm{a}$ & $2,02 \mathrm{ab}$ & $0,49 \mathrm{bc}$ & $13,83 \mathrm{ab}$ \\
\hline
\end{tabular}

Médias seguidas da mesma letra não diferem significativamente entre si pelo teste de Tukey, a 5\% de probabilidade

Analisando-se o extrato aquoso de leucena, verificou-se que este provocou efeito negativo sobre o crescimento da raiz de milho (Zea mays). Em bioensaios com gerbox, o comprimento da radícula e a parte aérea do milho se mostraram sensíveis ao extrato (PRATES et al., 2000). Demonstrando assim que, a leucena pode ter influência negativa em algumas espécies cultivadas, o que não foi verificado sobre sementes de soja.

Verificou-se que os extratos de leucena, provavelmente,nãoirãointerferirnodesenvolvimento normal da planta cultivada em questão se utilizada para controlar plantas invasoras presentes na plantação. Entretanto, segundo os autores acima citados, a soja pode ser influenciada por extratos de outras plantas, assim como o extrato de leucena pode influenciar algumas plantas cultivadas.

Com relação à soja, percebeu-se que os extratos de leucena não tiveram influência negativa em nenhum dos parâmetros analisados.

\section{Conclusões}

Nas condições em que foram realizados os experimentos pode-se concluir que, em laboratório, a leucena foi eficiente no controle de três das principais plantas invasoras que acometem as plantações de soja, a corda de viola, o picão-preto e a guanxuma, sem prejudicar a soja, podendo, possivelmente, ser utilizada como controle natural. 


\section{Referências}

ALMEIDA, F. S. Alelopatia e as plantas. Londrina: IAPAR, 1988.

AZANIA, A. A. P. M.; AZANIA, C. A. M.; PAVANI, M. C. D.; CUNHA, M. C. S. Métodos de superação de dormência em sementes de Ipomoea e Merremia. Planta Daninha, Viçosa, v. 21, n. 2, p. 203-209, 2003.

BORGES, L. M. ; BONALDO, S. M.; CRUZ, M. E. S. Efeitos alelopáticos de extratos vegetais medicinais sobre germinação de espécies invasoras. In: CONGRESSO SUL BRASILEIRO DE PLANTAS MEDICINAIS, 1., 1999, Maringá. Anais... Maringá: EDUEM, 1999. p. 46.

CHOU, C. H.; KUO, Y. L. Allelopathic research of subtropical vegetation in Taiwan. III. Alelopathic exclusion of understrory by Leucaena leucocephala (Lam.) de Wit. Journal of Chemical Ecology, New York, v. 12 , n. 6 , p. 1431-1448, 1986.

EDMOND, J. B.; DRAPALLA, W. J. The effects of temperature, sana and soil, and acetone on germination oj okra seed. Proceedings of the American Society for Horticultural Science, Alexandria, v. 71, n. 2, p. 428-443, 1958.

HADAS, A. Water uptake germination of leguminous seeds under changing external water potential in osmotic solution. Journal Experimental of Botany, Oxford, v. 27, n. 98, p. 480-489, 1976.

INSTITUTO HORUS DE DESENVOLVIMENTO E CONSERVAÇÃO. Leucaena leucocephala. 2003. Disponível em: <www.instituto horus.org.br>. Acesso em: 12 abr. 2006.

LABOURIAU, L. G. A germinação de sementes. Washington: Organização dos Estados Americanos, 1983.

LORENZI, H. Plantas daninhas do Brasil. 3. ed. Nova Odessa: Instituto Plantarum de estudos da flora, 2000.
MALLIK, M.; OLOFSDOTTER, A. U. Allelopathy symposium. Agronomy Journal, Madison, v. 93, n. 1, p. 1-2, 2001.

MONTEIRO, C. A.; VIEIRA, E. L. Substâncias alelopáticas. In: CASTRO, P. R. C.; SENA, J. O. A.; KLUGE, R. A. Introdução à fisiologia do desenvolvimento vegetal. Maringá: EDUEM, 2002. p. 105-122

PIMENTEL-GOMES, F. Curso de estatística experimental. Nobel: São Paulo, 1990.

PIRES, N. M; PRATES, H. T; PEREIRA FILHO, I. A. P; OLIVEIRA JUNIOR, R. S. O.; FARIA, T. C. L. Atividade alelopática de Leucena sobre espécies de plantas daninhas. Scientia Agrícola, Piracicaba, v. 58, n. 1, p. 61-65, 2001.

PRATES, H. T.; PAES, J. M. V.; PIRES, N. M.; PEREIRA FILHO, I. A.; MAGALHÃES, P. C. Efeito do extrato aquoso de leucena na germinação e no desenvolvimento do milho. Pesquisa Agropecuária Brasileira, Brasília, v. 35, n. 5, p. 909-914, 2000.

SCHERER, L. M.; ZUCARELI, V.; ZUCARELI, C. A.; FORTES, A. M. T. Efeito alelopático do extrato aquoso de folha e de fruto de leucena (leucaena leucocephla Wit) espécies invasoras. Semina: Ciências Agrárias, Londrina, v. 26 , n. 2, p. 153-158, 2005.

SIQUEIRA, J. C. Desafios éticos das plantas exóticas invasoras: Estudo de casos no estado do Rio de Janeiro. In: MARIATH, J. E. A.; SANTOS, R. P. Os avanços da botânica no início do século XXI: morfologia, fisiologia, taxonomia, ecologia e genética: conferências plenárias e simpósios do $57^{\circ}$ congresso nacional de botânica. Porto Alegre: Sociedade Botânica do Brasil, 2006. p. 510-513.

SOUZA FILHO, A. P. S.; RODRIGUES, L. R. A.; RODRIGUES, T. J. D. Efeito do potencial alelopático de três leguminosas forrageiras sobre três invasoras de pastagens. Pesquisa Agropecuária Brasileira, Brasília, v. 32, n. 2, p. 165-170, 1997. 